\title{
Incorporation of antimicrobial peptides on functionalized cotton gauzes for medical applications
}

\author{
A.P. Gomes ${ }^{\mathrm{a}}$, J.F. Mano ${ }^{\mathrm{b}, \mathrm{c}}$, J.A. Queiroz ${ }^{\mathrm{d}}$, I.C. Gouveia ${ }^{\mathrm{a}, *}$ \\ a FibEnTech - Fiber Materials and Environmental Technologies - Research Unit, Faculty of Engineering, University of Beira Interior, 6201-001 Covilhã, \\ Portugal \\ b 3B's Research Group - Biomaterials, Biodegradables and Biomimetics, University of Minho, Headquarters of the European Institute of Excellence on Tissue \\ Engineering and Regenerative Medicine, AvePark, 4806-909 Taipas, Guimarães, Portugal \\ ' ICVS/3B's - PT Government Associate Laboratory, Braga/Guimarães, Portugal \\ ${ }^{\mathrm{d}}$ Health Sciences Research Centre, University of Beira Interior, 6201-001 Covilhã, Portugal
}

\section{A R T I C L E I N F O}

\section{Article history:}

Received 29 September 2014

Received in revised form 25 March 2015

Accepted 31 March 2015

Available online 14 April 2015

\section{Keywords:}

Antimicrobial peptides

hBD-1

$\beta$-Defensin-1

Human

Dermaseptin

Cys-LC-LL-37

Magainin 1

Biocompatibility

Wound-dressing

\begin{abstract}
A B S T R A C T
A large group of low molecular weight natural compounds that exhibit antimicrobial activity has been isolated from animals and plants during the past two decades. Among them, peptides are the most widespread resulting in a new generation of antimicrobial agents with higher specific activity. In the present study we have developed a new strategy to obtain antimicrobial wound-dressings based on the incorporation of antimicrobial peptides into polyelectrolyte multilayer films built by the alternate deposition of polycation (chitosan) and polyanion (alginic acid sodium salt) over cotton gauzes. Energy dispersive $\mathrm{X}$ ray microanalysis technique was used to determine if antimicrobial peptides penetrated within the films. FTIR analysis was performed to assess the chemical linkages, and antimicrobial assays were performed with two strains: Staphylococcus aureus (Gram-positive bacterium) and Klebsiella pneumonia (Gram-negative bacterium). Results showed that all antimicrobial peptides used in this work have provided a higher antimicrobial effect (in the range of $4 \log -6 \log$ reduction) for both microorganisms, in comparison with the controls, and are non-cytotoxic to normal human dermal fibroblasts at the concentrations tested.
\end{abstract}

(c) 2015 Elsevier Ltd. All rights reserved.

\section{Introduction}

Several authors found that there was a significant absorption of antibiotic, when it is placed directly on the wound as a cream, which may increase the risk of cytotoxicity of the treated tissues, because in this case easily excessive amounts that can be used and it is difficult to control the optimal amount of cream. (Boosalis, McCall, Ahrenholz, Solem, \& McClain, 1987; Mi et al., 2002; Wang, Wang, Zhang, Zapatasirvent, \& Davies, 1985). Likewise, it is important to develop a method to control the release of antimicrobial agents.

It also has been reported that higher concentrations of some compounds are toxic to tissue and may be a burden to organs or lead to the development of antibiotic resistance (Boateng, Matthews, Stevens, \& Eccleston, 2008; Dave, Joshi, \& Venugopalan, 2012; Hidalgo \& Dominguez, 1998). Compounds most commonly incorporated into dressings to control or prevent infection are silver (Boateng et al., 2008), povidone-iodine (Misra \& Nanchahal,

\footnotetext{
* Corresponding author. Tel.: +35 1917248532.

E-mail address: igouveia@ubi.pt (I.C. Gouveia).
}

2003) and polyhexamethylene biguanide (Motta, Milne, \& Corbett, 2004). On the other hand, semi-solid preparations such as silver sulphadiazine cream (Hudspith \& Rayatt, 2004) and silver nitrate ointment (Moir \& Serra, 2012) are used to treat bacterial infection on the surface of the wound but direct application onto open wounds can be very painful (Thakoersing et al., 2012) and the scientific evidence for the efficacy of these agents in wounds is scarce. Common topical antibiotics also include mupirocin (Rode, Hanslo, Dewet, Millar, \& Cywes, 1989), neosporin (Sinha, Agarwal, \& Agarwal, 1997) and tetracycline (Kumar, Bai, \& Krishnan, 2004). However, these antibiotics are ineffective when resistant bacteria colonize the wound (Cookson, 1998; Hetem \& Bonten, 2013). Moreover, it is important that slow release of antimicrobial agent from wound dressing have the advantage of treating infected wounds in a mild way (Elsner, Berdicevsky, \& Zilberman, 2011; Kostenko, Lyczak, Turner, \& Martinuzzi, 2010).

Since the beginning of the antibiotic era in the 1940s, the use of antibiotics has resulted in the continual emergence of resistant strains of bacteria, further complicating the clearance of infection in cutaneous wounds (Gibson et al., 2012). Therefore, a new and innovative strategy is needed to combat infected cutaneous 
wounds. For this purpose a new strategy foresees the use of antimicrobial peptides (AMPs) as potential antibacterial for wound dressing application (Boateng et al., 2008). AMPs are a potential therapeutic compounds, they are essential components of the human innate immune system and as such contribute to the first line of defence against infections (Nizet et al., 2001; Zasloff, 2002).

AMPs produced in bacteria, insects, plants, invertebrates and vertebrates, are an important component of the natural defences of most living organisms. AMPs exhibit potent killing of a broad range of microorganisms, including Gram-negative and Gram-positive bacteria, fungi and viruses (Dai et al., 2010; Leguen et al., 2007; Marshall \& Arenas, 2003). AMPs are diverse in their sequence and structures. They are generally small (10-50 aminoacids) and have at least two positive charges (da Silva \& Machado, 2012). Besides antibacterial and antifungal activities, some of AMPs also possess antiviral or anticancer properties. AMPs exert their antifungal or antibacterial effects by interacting and destabilizing the microbial membrane, leading to cell death (Sato \& Feix, 2006; Wimley \& Hristova, 2011). The exact mechanism by which AMPs exert their antimicrobial properties is yet unknown, but it is generally accepted that cationic AMPs interact by electrostatic forces with the negatively charged phospholipid head groups on the bacterial membrane and cause disruption, resulting in bacterial killing (da Silva \& Machado, 2012; Zasloff, 2002).

There are different methods based on physical or chemical immobilization of AMPs to develop antibacterial surfaces. In covalent immobilization the AMPs chemically react with a given surface to form stable antimicrobial coatings (Onaizi \& Leong, 2011). Surfaces that are not reactive toward AMPs can undergo some surface treatment to introduce the desired functional groups that will allow the grafting of AMPs in a further step (Banerjee, Pangule, \& Kane, 2011). Among the physical immobilization methods Layer by Layer (LbL) can be a promising technique to immobilize AMPs on materials surfaces. This method is based on the alternate adsorption of polycations and polyanions on a solid substratum (Ariga, Hill, \& Ji, 2007). In this work AMPs can be simply embedded in the multilayer structure to prepare functional cotton gauzes.

From reports in the scientific literature, a group of 4 AMPs was selected for the present study: hBD-1, $\beta$-Defensin-1, human; Dermaseptin; Cys-LC-LL-37 and Magainin 1. All of these AMPs have been described to have an antimicrobial activity against different microorganisms (Guani-Guerra, Santos-Mendoza, Lugo-Reyes, \& Teran, 2010; Jiang et al., 2012; Nascimento, Franco, Oliveira, \& Andrade, 2012; Nicolas \& El Amri, 2009). Another important factor of these AMPs there are cysteine residues, which promote the formation of disulfide bonds in the molecular structure, making them resistant to proteases, temperature and $\mathrm{pH}$ (Bulet, Stocklin, \& Menin, 2004).

Defensins are cysteine-rich cationic antimicrobial peptides that play an important role in innate immunity they are known to contribute to the regulation of host adaptive immunity and capacity of re-epithelialisation of healing skin (Sakamoto et al., 2005).

Dermaseptin is a linear polyatomic peptide, composed of 34residue anionic, which are structured in amphipathic $\alpha$-helices in apolar solvents. Several Dermaseptins have been reported to inhibit the activity of microbial cells, rapidly, efficiently and irreversibly without toxic effects on mammalian cells (Marshall \& Arenas, 2003).

LL-37 induces keratinocyte migration required for reepithelialization of the wound. LL-37 is also an important factor in the proliferation and formation of vessel-like structures, and induces functional angiogenesis important for cutaneous wound neovascularization. LL-37 has antimicrobial activity against both Gram-positive and Gram-negative bacteria, stimulates wound vascularization and re-epithelialization of healing skin and has antitumor activity. The human cathelicidin LL-37 also has been associated with host stimulatory events important to the wound repair process (Izadpanah \& Gallo, 2005).

In this work we used a new line of LL-37 from AnaSpec, Inc., Cys-LC-LL-37. This is a new AMP like the LL-37, but has a broad range antimicrobial activity. This new AMP was obtained with one cysteine, where LC is a 6-carbon linker.

Magainin 1 is a 23-amino acid cationic AMP, which has a $\alpha-$ helical structure and is characterized by being a cationic and amphipathic molecule. Magainin 1 reveals multiple functions related to membrane interactions, being active toward multiple pathogens. This peptide also carries a positive net charge at a neutral $\mathrm{pH}$ level and has hydrophobic residues that are essential for antimicrobial activity (Nascimento et al., 2012; Speranza, Taddei, \& Ovidi, 2007). This AMP has broad-spectrum, nonspecific activity against a wide range of microorganisms, including viruses, Grampositive and Gram-negative bacteria, protozoa and fungi, may also be haemolytic and cytotoxic to cancer cells and is a bactericide (Zairi, Tangy, Bouassida, \& Hani, 2009). These observations suggest AMPs serve a dual role in wound healing: killing bacteria and stimulating complex host repair phenomena.

The biomaterials chosen for the functionalization of cotton gauze were chitosan $(\mathrm{CH})$ and alginic acid sodium salt (ALG), both known as biodegradable, nontoxic and biocompatible polymers. $\mathrm{CH}$ is widely used as wound dressings and has been shown to have mucoadhesive properties, cationic nature, anti-bacterial and haemostatic properties (Alves, Picart, \& Mano, 2009; Jayakumar et al., 2010).

ALG is known to be nontoxic, having hemostatic action and biocompatible with a variety of cells, ALG has been studied for application as biomaterials and as wound dressings (de Moraes \& Beppu, 2013). Due to its properties CH and ALG are already widely used in biomedical applications (Caridade et al., 2013; Lee \& Mooney, 2012; Martins, Merino, Mano, \& Alves, 2010).

An ideal wound dressing can restore the milieu required for the healing process, while simultaneously protecting the wound bed against bacteria. This has encouraged the development of improved wound dressings that provide an antimicrobial effect by eluting germicidal compounds such as iodine or most frequently silver ions. Such dressings are designed to provide controlled release of the active agent through a slow but sustained release mechanism which helps to avoid toxicity and yet ensures delivery of a therapeutic dose to the wound (Peles, Binderman, Berdicevsky, \& Zilberman, 2013).

Based on the previous concept, in this study, we have incorporated AMPs onto a substrate of cotton gauze functionalized with layers of $\mathrm{CH}$ and ALG. Functionalized cotton gauzes with $\mathrm{CH}$ and ALG were obtained via LbL electrostatic deposition, as described in a work already published (Gomes, Mano, Queiroz, \& Gouveia, 2012). The aim of this work is to incorporate AMPs between the layers of $\mathrm{CH}$ and ALG. These layers are based on the alternate deposition of oppositely charged polyelectrolyte layers $(\mathrm{CH}$ is a polycation and ALG is a polyanion), this deposition was made on cotton gauze.

The embedding of active agents by LbL is a very recent area of research receiving great interest due to the advantage of obtaining control over drug release. Not so recent and with a large number of published papers, LbL was developed for drug delivery systems through microcapsules (Johnston, Cortez, Angelatos, \& Caruso, 2006; Quinn, Johnston, Such, Zelikin, \& Caruso, 2007; Sukhishvili, 2005; Tang, Wang, Podsiadlo, \& Kotov, 2006; Wang, Angelatos, \& Caruso, 2008). LbL deposited thin films were first developed by Decher and co-workers (Decher, 1997). They proposed a protocol for the preparation of thin films based on alternate and repeated adsorption of polycations and polyanions on the surface of a solid substrate from solution. A diversity of materials have been employed as building blocks for LbL films, including synthetic polymers, biopolymers, inorganic nanoparticles, etc. (Ariga et al., 
Table 1

Structure for AMPs.

\begin{tabular}{|c|c|c|}
\hline Peptide & Size (kDa) & Amino acid sequence \\
\hline hBD-1, $\beta$-Defensin-1, human & 3.9 & DHYNCVSSGGQCLYSACPIFTKIQGTCYRGKAKCCK (Disulfide bridge: 5-34, 12-27, 17-35) \\
\hline Dermaseptin & 3.4 & ALWKTMLKKLGTMALHAGKAALGAAADTISQGTQ \\
\hline Cys-LC-LL-37 & 4.7 & C-LC-LLGDFFRKSKEKIGKEFKRIVQRIKDFLRNLVPRTES \\
\hline Magainin 1 & 2.4 & GIGKFLHSAGKFGKAFVGEIMKS \\
\hline
\end{tabular}

2007). Consequently, a variety of components and functionality can be incorporated into LbL films, which forms the basis for the development of stimuli-sensitive LbL films for drug delivery.

\section{Materials and methods}

\section{1. $A M P S$}

Sequence of the AMPs used is shown in Table 1. The lots containing lyophilized powder of hBD-1, $\beta$-Defensin-1, human (ANASPEC); Dermaseptin (ANASPEC); Cys-LC-LL-37 (ANASPEC) and Magainin 1 (ANASPEC) were stored at $-20^{\circ} \mathrm{C}$. When the AMPs solution was prepared the content present in the lots $(1 \mathrm{mg})$ was dissolved in $1 \mathrm{~mL}$ of sterile water and a stock solution of AMPs of $10 \mu \mathrm{g} / \mathrm{mL}$ was prepared.

\subsection{Determination of minimal inhibitory concentration (MIC)}

By definition MIC is the lowest concentration of antimicrobial agent that prevents the visible growth of a microorganism on susceptibility testing. MICs were determined using the broth microdilution method, as described by CLSI M7-A7 standard method for bacterial strains Staphylococcus aureus (ATCC 25923) and Klebsiella pneumonia (ATCC 13883) (Matthew, Wikler, \& William, 2006). According to the guidelines, the MIC was determined by serial dilution (1:2) in Mueller-Hinton Broth (MHB). The inoculum was prepared from fresh overnight liquid cultures and the turbidity was adjusted to obtain turbidity to 0.5 McFarland (approximately $1 \times 10^{8} \mathrm{CFU} / \mathrm{mL}, \mathrm{CFU}=$ colony forming units) with $0.85 \% \mathrm{NaCl}$ and microorganisms, and then diluted to give a final concentration of $1 \times 10^{5} \mathrm{CFU} / \mathrm{mL}$. For this $10 \mu \mathrm{L}$ of bacterial suspension, $990 \mu \mathrm{L}$ of MHB was added. After the preparation of the bacterial suspension, a solution of AMPs of the initial concentration $10 \mu \mathrm{g} / \mathrm{mL}$ was used as starting point to perform the successive volumetric dilutions in a ratio of $1: 2$. To each well of the microdilution, $50 \mu \mathrm{L}$ of the work suspension was added with $50 \mu \mathrm{L}$ of AMPs in different dilutions. Inoculated microdilution was incubated at $35^{\circ} \mathrm{C}$ for $16-20 \mathrm{~h}$.

\subsection{Polyelectrolyte multilayer film preparation and AMPs incorporation}

Sterile cotton gauzes obtained from Albino Dias de Andrade, Lda (www.ADA.pt) were used as substrate. (2,2,6,6tetramethylpiperidin-1-yl)oxyl designated by TEMPO, Sodium Bromide (NaBr), Sodium Hypochlorite ( $\mathrm{NaOCl}$ ) 5\%, CH (low molecular weight, $50-190 \mathrm{kDa}$ and $80 \%$ degree of deacetylation), Acetic Acid $\left(\mathrm{CH}_{3} \mathrm{COOH}\right)$, ALG (molecular weight $120-190 \mathrm{kDa}$, ratio of mannuronic acid to guluronic acid is 1.56 and viscosity $15-20 \mathrm{cP}$, $1 \%$ in $\mathrm{H}_{2} \mathrm{O}$ ), sodium chloride $(\mathrm{NaCl})$, sodium hydroxide $(\mathrm{NaOH})$ and hydrochloric acid $(\mathrm{HCl})$ were purchased from Sigma-Aldrich. All chemicals were of analytical grade and used as received. Polyelectrolyte $\mathrm{CH}(1 \mathrm{mg} / \mathrm{mL})$ and ALG $(1 \mathrm{mg} / \mathrm{mL})$ solutions were prepared by dissolving $\mathrm{CH}$ and ALG in $0.1 \mathrm{M} \mathrm{CH} \mathrm{CH}_{3} \mathrm{COOH}$ and $0.5 \mathrm{M} \mathrm{NaCl}$ solutions, respectively. To apply LbL technique, cotton gauzes were charged by immersing in (TEMPO $+\mathrm{NaBr}+\mathrm{NaClO} 5 \%, \mathrm{pH}=10.5)$ solution under moderate stirring, for $30 \mathrm{~min}$, followed by a rinse with deionized water, as described elsewhere (Dang, Zhang, \& Ragauskas, 2007; Diez et al., 2011; Gomes et al., 2012; Saito, Okita, Nge, Sugiyama, \& Isogai, 2006).

Samples were manually prepared by immersing the cotton gauze substrate alternately in polycation and polyanion solutions, for $5 \mathrm{~min}$. Between each polyelectrolyte exposure, the sample was rinsed with deionized water. For the $\mathrm{CH}$ and ALG polyelectrolyte layers, a pH of 5.0 was selected, to be approximately an intermediate value between the $K_{\mathrm{a}}$ of $\mathrm{CH}(6.3)$ and ALG (3.38 and 3.65 for different residues) (Maurstad, Morch, Bausch, \& Stokke, 2008).

Functionalization of cotton gauzes was prepared with four layers (cotton gauze/CH/ALG/CH/ALG), according with the optimization made in our previous work (Gomes, Mano, Queiroz, \& Gouveia, 2010; Gomes et al., 2012; Gomes, Mano, Queiroz, \& Gouveia, 2013; Gomes, Mano, Queiroz, \& Gouveia, 2014). Then, the functionalized cotton gauze was immersed in a solution of AMPs in concentration higher than the MIC values, $10 \mu \mathrm{g} / \mathrm{mL}$ for $24 \mathrm{~h}$. The selected concentration aimed to ensure that a significant amount would be absorb, giving the expected antimicrobial activity. Absorption rates of the AMPs were monitored after 6, 12, 18 and $24 \mathrm{~h}$ through the Bradford method described in Section 2.8. The functionalized samples of cotton gauzes were washed with deionized water containing calcium in order to occur the ALG gel formation, finally a final $\mathrm{CH}$ layer was added. With this procedure we were able to obtain the expected coating with embed AMPs.

Note that previous work reported by Deng et al. (2010), where the LbL method was assembled on cellulose (main constituent of cotton) nanofiber highly compact and crystalline surface obtained by electrospinning, the estimated thickness of CH/ALG bilayer formed on fibers was in the range of $8-15 \mathrm{~nm}$. For the same polyelectrolytes ( $\mathrm{CH}$ and $\mathrm{ALG}$ ), a study on polypropylene substrate showed the thickness of $160 \mathrm{~nm}$ (Caridade et al., 2013) and in quartz substrate the thickness of CH/ALG was found to be $15 \mathrm{~nm}$ (Martins, Mano, \& Alves, 2010).

Actually, in linearly growth of layer thickness each bilayer interacts only with bilayers that directly neighbor it (above or below) with very little inter-penetration. However, there are systems that showed exponential increases in film thickness with each deposition cycle, this type of growth was attributed to a diffusion of polyelectrolyte "in" and "out" of the film during each bilayer step (Foster \& DeRosa, 2014), which is the case of cotton porous fibers whereas polyelectrolyte diffusion is expected. The typical thickness of a linearly growing film constituted of 20 bilayers is of the order of $100 \mathrm{~nm}$ but the thickness of exponentially growing films can reach $10 \mu \mathrm{m}$ or more after the deposition of a similar number of layers (Richert et al., 2004) which is in accordance with the thickness values found by us. In these functionalized cotton gauzes we have shown that there is an exponential growth of the layers resulting in a coating thickness in range of $0.6-1 \mu \mathrm{m}$ (four layers or two bilayers), as can be seen in the TEM image of Fig. 1. The samples were examined using a HITACHI HT 7700 TEM.

\subsection{Energy dispersive $X$ ray microanalysis technique}

Energy dispersive $\mathrm{X}$ ray microanalysis technique (EDX) has been a common elemental analysis method used to determine the composition of particles and thin films in sample analysis. EDX 


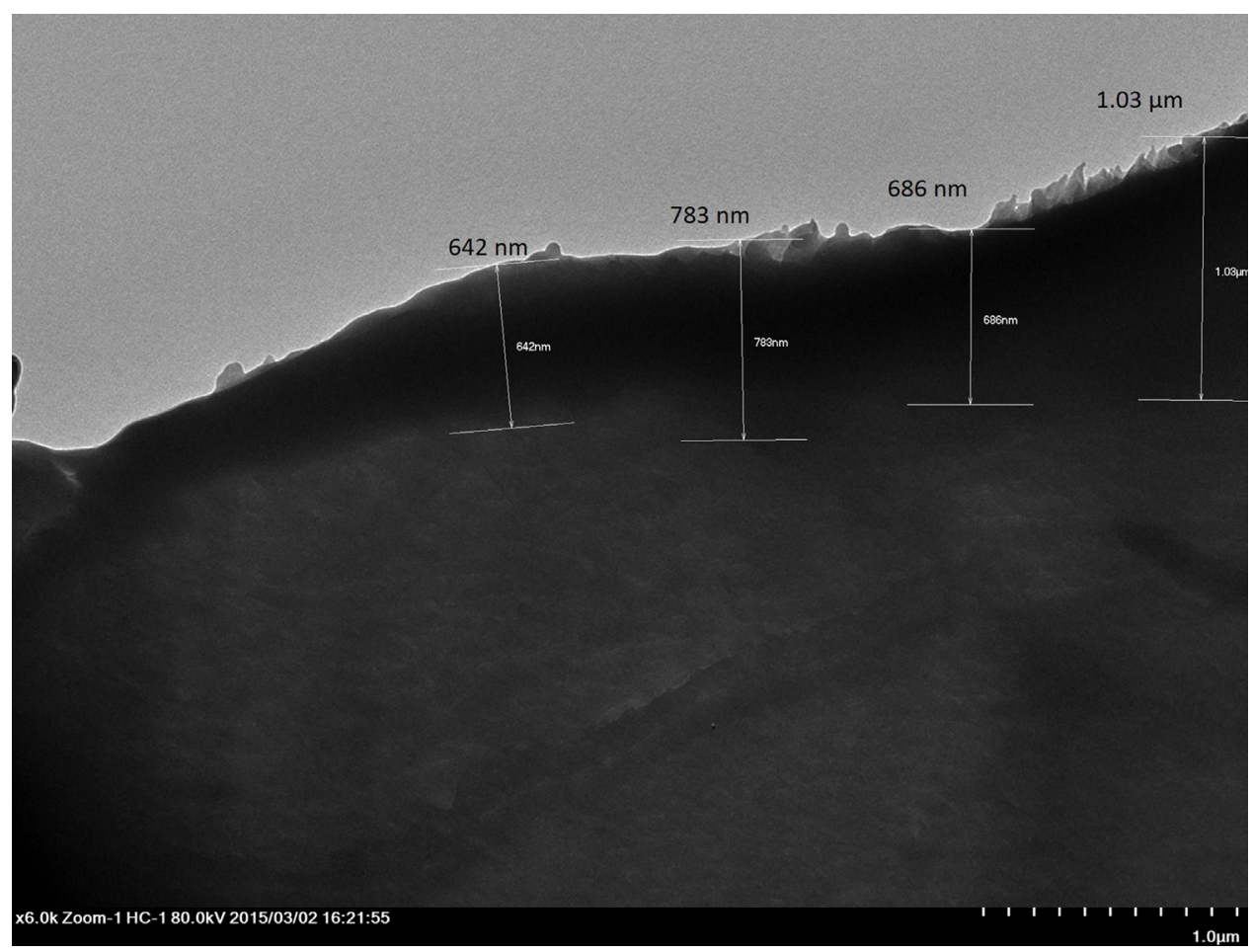

Fig. 1. TEM image of sample cotton/CH/ALG/CH/ALG.

technique is based on volume analysis, and as such, the electron penetration of the specimen is a direct function of acceleration beam voltage and sample density. The accelerating voltage determines the force of the electron beam. In general, one can see that as the electron beam voltage increases, the penetration depth increases. Higher accelerating voltages, which apply more force to the electrons in the beam, can allow them to penetrate deeper into the sample. For example, using 5, 10, 15, 20, 25 and $30 \mathrm{kV}$ acceleration voltages for carbon sample, penetration depth is about 0.34 , $1.20,2.2,4.10,6.1$ and $8.5 \mu \mathrm{m}$ respectively (Hua, 2004; Lee, Hua, Zhao, \& Mo, 2006).

In this study, Scanning Electron Microscopy (SEM) and EDX analyses were carried out on a Hitachi S 2700 using different electron beam accelerating voltages and $12 \mathrm{~mm}$ working distance.

\subsection{ATR-FTIR spectra}

All samples were analyzed in absorption mode using a Nicolet iS 10 FT-IR spectrometer (Thermo Scientific) accommodated with a smart ITR accessory for ATR sampling. The smart ITR accessory is equipped with a single bounce diamond crystal. Prior to spectrum recording the sample was pressed directly on the diamond crystal by usage of the smart, ITR high pressure clamp. Each spectrum was measured at a spectral resolution of $4 \mathrm{~cm}^{-1}$ with 64 scans per spectrum. Spectrum recording was performed in the range of $4000-600 \mathrm{~cm}^{-1}$. A spectrum was obtained in three different locations for each sample to ensure even chemical composition. Before each sample a blank was measured to check the crystal for contamination. Every hour a background spectrum was measured against air using identical instrumental conditions as the samples. Spectral data were obtained using the OMNIC Software (Thermo Scientific). After each measurement, the crystal was cleaned using a soft tissue soaked with ethanol and left to dry in ambient air.

ATR-FTIR reveals information about the molecular structure of chemical compounds and is useful for the characterization of biopolymers. These analyses were made in order to investigate the way the AMPs were incorporated between the layers of $\mathrm{CH} / \mathrm{ALG}$ of functionalized cotton gauzes.

\subsection{Assessment of antibacterial activity}

The AMPs antibacterial effect of functionalized cotton gauzes with $\mathrm{CH} / \mathrm{ALG}$ was tested according to the Japanese Industrial Standard JIS L 1902:2002 (Standard, 2002), which is the most employed method. This method is designed to quantitatively test the ability of textiles that have been treated with antibacterial agents to prevent bacterial growth and to kill bacteria, over an $18 \mathrm{~h}$ period of contact. This method is based on the quantitative determination of the potential effect and activity of functionalized samples, by the direct contact with a suspension of bacterial cells.

The cotton gauze sample sizes are approximately $18 \mathrm{~mm} \times 18 \mathrm{~mm}$. We prepared 6 control samples with CH/ALG and without AMPs and 6 functionalized samples with CH/ALG and AMPs, these samples were tested for each bacterial strain. In order to calculate growth reduction rate, three samples were used to measure the number of live bacteria after inoculation $\left(T_{0 \mathrm{~h}}\right)$ and the other three to measure the number of live bacteria after incubation $\left(T_{18 \mathrm{~h}}\right)$.

Bacterial cell suspensions were collected from an overnight liquid culture in Nutrient Broth. After that, the bacterial concentration is adjusted to $1-2 \times 10^{8} \mathrm{cel} / \mathrm{mL}$ (equivalent to $0.5 \mathrm{McFarland}$ ), with the necessary dilutions to adjust the final bacterial concentration to $1 \pm 0.3 \times 10^{5} \mathrm{cel} / \mathrm{mL}$.

Each sample was placed in a $50 \mathrm{~mL}$ Falcon tube, soaked with $200 \mu \mathrm{L}$ of the inoculum previously prepared, $T_{18 \mathrm{~h}}$ tubes were incubated for $18 \mathrm{~h}$ at $37^{\circ} \mathrm{C}$. For the release of bacterial cells from the cotton gauze samples, before and after the $18 \mathrm{~h}$ incubation period, $20 \mathrm{~mL}$ of $0.85 \% \mathrm{NaCl}$ with surfactant Tween $80(0.2 \%)$ was added to the samples in $50 \mathrm{~mL}$ Falcon tubes and vortexed. The resulting suspensions were used for the determination of viable counts using serial dilutions prepared in sterile $0.85 \%$ sodium chloride solution and plated. The plates were incubated at $37^{\circ} \mathrm{C}$ for $18 \mathrm{~h}$, 
and the number of colonies was counted visually using a microscope. This procedure was performed in triplicate (Standard, 2002). The growth reduction rate of the bacteria was calculated using the equation:

$\frac{T_{0 \mathrm{~h}}-T_{18 \mathrm{~h}}}{T_{0 \mathrm{~h}}} \times 100 \%=$ reduction rate(\%)

where, $T_{0 \mathrm{~h}}$ is the $\mathrm{CFU} / \mathrm{mL}$ of bacterial colonies at the initial stage $(0 \mathrm{~h})$ and $T_{18} \mathrm{~h}$ is the $\mathrm{CFU} / \mathrm{mL}$ of bacterial colonies after $18 \mathrm{~h}$ incubation (Park \& Park, 2010).

\subsection{Cytotoxicity assay}

The possibility of application of these functionalized samples as wound dressings is also evaluated by cytotoxicity test. Cytotoxicity of the AMPs was evaluated by an MTT (3-[4,5-dimethyl-thiazol2-yl]-2,5-diphenyltetrazolium bromide) viability assay (Freshney, 2005) using normal human dermal fibroblasts (NHDF), since the textile material is intended to be in contact with the human skin. Cells were routinely maintained at $37^{\circ} \mathrm{C}$ in a humidified atmosphere containing $5 \% \quad \mathrm{CO}_{2}$ and cultured in RPMI medium supplemented with $10 \%$ fetal bovine serum (FBS), HEPES $(0.01 \mathrm{M})$, L-glutamine $(0.02 \mathrm{M})$ and sodium pyruvate $(0.001 \mathrm{M})$ and $1 \%$ antibiotic/antimycotic $(10,000$ units $/ \mathrm{mL}$ penicillin, $10 \mathrm{mg} / \mathrm{mL}$ streptomycin and $25 \mu \mathrm{g} / \mathrm{mL}$ amphotericin B). Experiments were performed in 24-well tissue culture plates with $2 \times 10^{4}$ cells/well. Cells were used on the 20th passage.

Briefly, cells were seeded in 24 -well plates $\left(2 \times 10^{4}\right.$ cells/well $)$ in culture medium containing FBS and after $48 \mathrm{~h}$ adherence, some wells were treated with concentrations of hBD-1, $\beta$-Defensin1; Dermaseptin and Cys-LC-LL-37 of $5.00 \mu \mathrm{g} / \mathrm{mL}$, and Magainin 1 with two concentrations of 0.20 and $4.17 \mu \mathrm{g} / \mathrm{mL}$ and incubated at $37^{\circ} \mathrm{C}$, in a $5 \% \mathrm{CO}_{2}$ atmosphere, for $48 \mathrm{~h}$. The concentrations chosen were the MIC values against S. aureus and Klebsiella pneumoniae. Untreated cells were used as control. Afterwards the liquid content of the wells was removed and it was replaced with $200 \mu \mathrm{L}$ of MTT solution of $1 \mathrm{mg} / \mathrm{mL}$ in PBS. The multi-well plates were incubated for $4 \mathrm{~h}$, at $37^{\circ} \mathrm{C}$, with a $5 \% \mathrm{CO}_{2}$ atmosphere, in the dark. Next, the content of the wells was removed and it was added $200 \mu \mathrm{L}$ of DMSO and $20 \mu \mathrm{L}$ of Glicil-Glicin buffer to dissolve the formazan cristals and to stabilize the color, respectively. The absorbance of each well was measured at $570 \mathrm{~nm}$ using a Biochrom Anthos 2020 microplate reader. The extent of cell viability was expressed as the percentage of viable treated cells in comparison with control cells. All experiments were done in triplicate.

The cytotoxicity results were submitted to a Student's $t$-test in 95\% confidence interval, using the computer software, IBM SPSS Statistics for Windows (version 19.0). $p$-Values $<0.05$ were considered statistically significant.

\subsection{Absorption/desorption rates of the AMPs (Bradford reagent)}

The absorption and release of the AMPs into and from samples was determined using the colorimetric assay of Bradford reagent. The procedure is based on the formation of a complex between the dye, Coomassie Brilliant Blue G, and proteins (AMPs) in solution. The protein-dye complex causes a shift in the absorption maximum of the dye from 465 to $595 \mathrm{~nm}$. The amount of absorption/desorption is proportional to the protein present (Bradford, 1976).

The Bradford method is the most commonly used in quantitative protein determination. This method is popular because it uses a single addition of the dye reagent to the sample, it is rapid and it is done at room temperature. However, it is still an open question how reliable this method is if the formulation also involves polymer excipients. Carlsson, Borde, Wolfel, Akerman, \& Larsson, 2011,
Table 2

MICs of AMPs for Staphylococcus aureus and Klebsiella pneumoniae.

\begin{tabular}{lll}
\hline MIC $(\mu \mathrm{g} / \mathrm{mL})$ & Staphylococcus aureus & Klebsiella pneumoniae \\
\hline hBD-1, $\beta$-Defensin-1, human & 5.00 & 5.00 \\
Dermaseptin & 5.00 & 5.00 \\
Cys-LC-LL-37 & 5.00 & 5.00 \\
Magainin 1 & 0.20 & 4.17 \\
\hline
\end{tabular}

demonstrated the potential perturbations in the Bradford assay by chitosan which can interact directly with the anionic Coomassie Blue dye and perturbs its absorption spectrum. They also found that above $5 \mu \mathrm{g} / \mathrm{mL}$ chitosan is not as critical as at chitosan concentrations below $5 \mu \mathrm{g} / \mathrm{mL}$ (Carlsson et al., 2011).

To overcome this problem in this work two standards curves are prepared. Firstly a calibration curve was made using bovine serum albumin (BSA) with selected concentrations $(0,2.5,5,7.5$ and $10 \mu \mathrm{g} / \mathrm{mL}$ ). Secondly a calibration curve was made with the same substrate (cotton/CH/ALG) as the final samples. So, cotton/CH/ALG samples were used with various concentrations of BSA as standards. The Bradford reagent was then added and to each tube containing $1 \mathrm{~mL}$ of the sample it was added $1 \mathrm{~mL}$ of dye and mixed thoroughly. After $15 \mathrm{~min}$ incubation, the absorbance of each sample was read at $595 \mathrm{~nm}$ wavelength, and for each concentration of BSA three independent measurements were made and the best estimate taken as their mean. The concentration of AMPs in the solution was determined by a calibration curve using standard protein BSA. The absorption rate concentrations were estimated through the difference of the amount of AMPs in the solution before $(10 \mu \mathrm{g} / \mathrm{mL})$ and after the sample immersion. For the release assay, absorbance was monitored for $1,2,3,4,6,12$ and $24 \mathrm{~h}$, directly on a solution containing the functionalized cotton gauzes immersed in a $20 \mathrm{~mL}$ of $0.85 \% \mathrm{NaCl}$, in order to establish the release profile for each AMPs incorporated.

\section{Results and discussion}

\subsection{Determination of minimal inhibitory concentration (MIC)}

MIC is important to confirm resistance of microorganisms to an antimicrobial agent and also to monitor the activity of new antimicrobial agents. Table 2 shows the calculated values of the MICs of AMPs for S. aureus and K. pneumonia. The data indicate that MIC values for hBD-1, $\beta$-Defensin-1, human; Dermaseptin and Cys-LCLL-37 are identical for the two microorganisms, being $5.00 \mu \mathrm{g} / \mathrm{mL}$ to $S$. aureus and $5.00 \mu \mathrm{g} / \mathrm{mL}$ to K. pneumonia. For Magainin 1 the MIC value was $0.20 \mu \mathrm{g} / \mathrm{mL}$ for $S$. aureus while for $K$. pneumonia was $4.17 \mu \mathrm{g} / \mathrm{mL}$. Thus, is visible that all AMPs exhibit MIC values very low, which is a major benefit in comparison with other antimicrobial agents for wound dressings.

The MIC value found in the literature for $\beta$-Defensin and Dermaseptin was a value of $10 \mu \mathrm{g} / \mathrm{mL}$ for Gram-positive and Gramnegative bacteria (Li, Zhao, Song, Huang, \& Zhao, 2013; Zairi, Tangy, Ducos-Galand, Alonso, \& Hani, 2007), twice high to that found by us. In previous works, LL-37 showed a MIC value of $3.6 \mu \mathrm{g} / \mathrm{mL}$ for S. aureus and MIC values between 0.4 and $5.7 \mu \mathrm{g} / \mathrm{mL}$ for Gramnegative bacteria (De Smet \& Contreras, 2005).

Among the different AMPs tested, we found that Magainin 1 was the more potent to inhibit $S$. aureus growth with the lowest MIC value of $0.20 \mu \mathrm{g} / \mathrm{mL}$.

\subsection{Energy dispersive $X$ ray microanalysis technique}

The functionalized samples of cotton gauze were analyzed by different values of beam acceleration voltages $(5,10,15,20,25$ and $30 \mathrm{kV}$ ) to determine if each AMPs diffuses between the layers 
Table 3

EDS analysis (beam accelerating voltages, kv vs. percentage elemental of sulfur, wt\%) for the functionalized cotton gauzes in AMPs solutions, overtime (18 and $24 \mathrm{~h}$ ).

\begin{tabular}{|c|c|c|c|c|c|c|}
\hline & $\%$ Sulfur (5 kV) & \%Sulfur (10 kV) & \%Sulfur (15 kV) & \%Sulfur (20 kV) & \%Sulfur (25 kV) & $\%$ Sulfur (30 kV) \\
\hline \multicolumn{7}{|l|}{$18 \mathrm{~h}$ of absorption of the AMPs } \\
\hline hBD-1, $\beta$-Defensin-1, Human & 0 & 0 & $0.51 \pm 0.10$ & $0.19 \pm 0.10$ & 0 & 0 \\
\hline Dermaseptin & 0 & $0.20 \pm 0.07$ & $0.09 \pm 0.06$ & 0 & 0 & 0 \\
\hline Cys-LC-LL-37 & 0 & 0 & $0.22 \pm 0.05$ & $0.09 \pm 0.06$ & 0 & 0 \\
\hline Magainin 1 & 0 & 0 & $0.10 \pm 0.05$ & $0.27 \pm 0.10$ & $0.08 \pm 0.08$ & 0 \\
\hline Control & 0 & 0 & 0 & 0 & 0 & 0 \\
\hline \multicolumn{7}{|l|}{$24 \mathrm{~h}$ of absorption of the AMPs } \\
\hline hBD-1, $\beta$-Defensin-1, Human & 0 & 0 & $0.54 \pm 0.10$ & $0.25 \pm 0.09$ & 0 & 0 \\
\hline Dermaseptin & 0 & $0.25 \pm 0.08$ & $0.10 \pm 0.05$ & 0 & 0 & 0 \\
\hline Cys-LC-LL-37 & 0 & 0 & $0.28 \pm 0.07$ & $0.10 \pm 0.04$ & 0 & 0 \\
\hline Magainin 1 & 0 & 0 & $0.12 \pm 0.04$ & $0.30 \pm 0.10$ & $0.10 \pm 0.05$ & 0 \\
\hline Control & 0 & 0 & 0 & 0 & 0 & 0 \\
\hline
\end{tabular}

of $\mathrm{CH}$ and ALG. This analysis was performed by determining the elemental percentage of sulfur, because sulfur is the only chemical element that is present in each AMPs and is not present in cotton gauze, $\mathrm{CH}$ and ALG. These values are summarized into Table 3, from which it can be seen that there is a diffusion of the different AMPs in the functionalized cotton gauzes.

Fig. 5(a) shows the absorption kinetic of AMPs into functionalized cotton gauze, where it can be seen that the equilibrium phase is between $18-24 \mathrm{~h}$, being therefore the selected time for the EDX analysis. Analyzing the values in Table 3 it can be seen that for immersion times of 18 and $24 \mathrm{~h}$ there are no differences on the AMPs diffusion depth, only a slight increase in the \% of sulfur from 18 to $24 \mathrm{~h}$, due to higher amount absorbed overtime.

This method constitutes a starting point for determining the conditions for optimizing the process of incorporation of the AMP for a particular application and to monitor the diffusion and attachment of the AMPs into the $\mathrm{CH} / \mathrm{ALG}$ layers with success. This analysis is in agreement with other published works by Hua (2004) that used the EDX analysis in various materials to evaluate the depth of penetration of the electron beam, for example the study of semiconductor and analysis of thin film layers $\left(\mathrm{Si}_{3} \mathrm{~N}_{4}, \mathrm{SiO}_{2}\right.$ and $\left.\mathrm{TiW}\right)$ in wafer fabrication (Hua, 2004; Lee et al., 2006).

\subsection{ATR-FTIR spectra}

Fig. 2 shows characteristic cellulose peaks around $1000-1200 \mathrm{~cm}^{-1}$, which are the main components of cotton (Chung, Lee, \& Choe, 2004; Wang, Fan, Gao, \& Chen, 2006; Yan et al., 2009). Other characteristic bands related to the chemical structure of cellulose were hydrogen - bonded $\mathrm{OH}$ stretching around $3100-3550 \mathrm{~cm}^{-1}$, the $\mathrm{C}-\mathrm{H}$ stretching around $2800 \mathrm{~cm}^{-1}$ and the asymmetrical $\mathrm{COO}^{-}$stretching around $1600 \mathrm{~cm}^{-1}$, if the carboxylate existed in ionized form $\left(\mathrm{COO}^{-}\right)$, it would show two peaks at 1600 and $1400 \mathrm{~cm}^{-1}$ for the asymmetric and the symmetric stretching of $\mathrm{COO}^{-}$ion, respectively (Chung et al., 2004; Wang et al., 2006; Yan et al., 2009; Zhao, Tang, Wang, \& Lin, 2010).

Absorptions in the region $3200-2700 \mathrm{~cm}^{-1}$, if the main absorption is below $3000 \mathrm{~cm}^{-1}$, the compound is probably aliphatic and probably contains a long linear aliphatic chain (Coates, 2000). In Fig. 2(b)-(e) it is found that this band decreases in intensity relatively the same band in Fig. 2(a), maybe due to the breaking of long aliphatic chain during the AMPs embedding.

Absorptions in the region $1850-1650 \mathrm{~cm}^{-1}$ more specifically in the range of $1750-1700 \mathrm{~cm}^{-1}$, means that the compound is probably a simple carbonyl compound or a carboxylic acid (Coates, 2000). It was observed in Fig. 2(b)-(e) that this peak is slightly shifted to lower values, meaning that there is a conjugation with another carbonyl group or aromatic ring, indicating the presence of AMPs.

In Fig. 2(b)-(e) it can be noted the presence of peaks at 1558 and $1600 \mathrm{~cm}^{-1}$ (marked with an arrow in Fig. 2). In Fig. 2(a) the peak around $1600 \mathrm{~cm}^{-1}$ is typical of the antisymmetric stretching of $\mathrm{COO}^{-}$group of ALG. In Fig. 2(b)-(e) in addition of $1600 \mathrm{~cm}^{-1}$ there is a peak around $1558 \mathrm{~cm}^{-1}$ corresponding the $\mathrm{NH}$ amide group of AMPs because the peak around $1420 \mathrm{~cm}^{-1}$ is characteristic for $\mathrm{CH}$ amide (Mocanu, Nichifor, Mihai, \& Oproiu, 2013). Note that the peak around $1558 \mathrm{~cm}^{-1}$ is also due to aromatic ring (AMPs).

Finally, it can also be observed that the AMPs are not bound to $\mathrm{CH}$ and ALG, so the AMPs are able to be released, which can be an important issue as a requirement of antimicrobial activity for a wound-dressing.

\subsection{Assessment of antibacterial activity}

Fig. 3 shows the growth inhibition (cell reduction) of the $S$. aureus and K. pneumonia by the antibacterial activity of the cotton gauzes, designated $\mathrm{CO}$ (without $\mathrm{CH} / \mathrm{ALG}$ and AMPs); functionalized sample of cotton gauzes with $\mathrm{CH} / \mathrm{ALG}$, designated control; and functionalized cotton gauzes with $\mathrm{CH} / \mathrm{ALG}$ and AMPs. The incorporation of each AMPs was performed by incubation for $24 \mathrm{~h}$ on solution by functionalized cotton gauzes with $\mathrm{CH} / \mathrm{ALG}$.

Analyzing the results (Fig. 3), it appears that cotton gauze (CO) have some reduction of growth inhibition (20\%) of S. aureus and $K$. pneumonia, this is because cotton in solution has a negative charge. We can see in Fig. 3 that functionalized cotton gauzes with hBD-1, $\beta$-Defensin 1 ; Cys-LC-LL-37 and Magainin 1 have growth inhibition similar for the two microorganisms, these values show the bactericidal power of AMPs. These samples have an increase about $20-30 \%$ in growth inhibition for two bacteria relatively samples without AMPs. Despite the fact that AMPs cause an increase of $20-30 \%$ in reduction of bacterial growth, it is important to achieve a $6 \log$ reduction to be consider a very good antimicrobial textile material. In addition, there are several benefits in use AMPs in wound healing. The continuous use of antibiotics has resulted in multi-resistant bacterial strains all over the world. Consequently, there is an urgent need to search for alternatives to synthetic antibiotics. AMPs are an effective alternative because until today it was not been proven that AMPs induce resistance. Other advantages of AMPs in wound dressings include pain relief, reduction of inflammation, angiogenesis and acceleration of the healing process.

Functionalized cotton gauzes with Dermaseptin has lower growth inhibition rate for the two microorganisms. In this case there is a minor increase in growth inhibition for K. pneumonia and no increase in growth inhibition for $S$. aureus, possibly is due to Dermaseptin is an anionic peptide, giving him low antibacterial activity, and due to repulsion between negative charge of Dermaseptin and negative charge of ALG (layer directly involved in the process of incorporating AMPs), which led to the entrance of a small amount of Dermaseptin between multilayers of $\mathrm{CH}$ and ALG.

The indications of US FDA and their European counterparts consider that exist antibacterial properties in the case of bacterial 


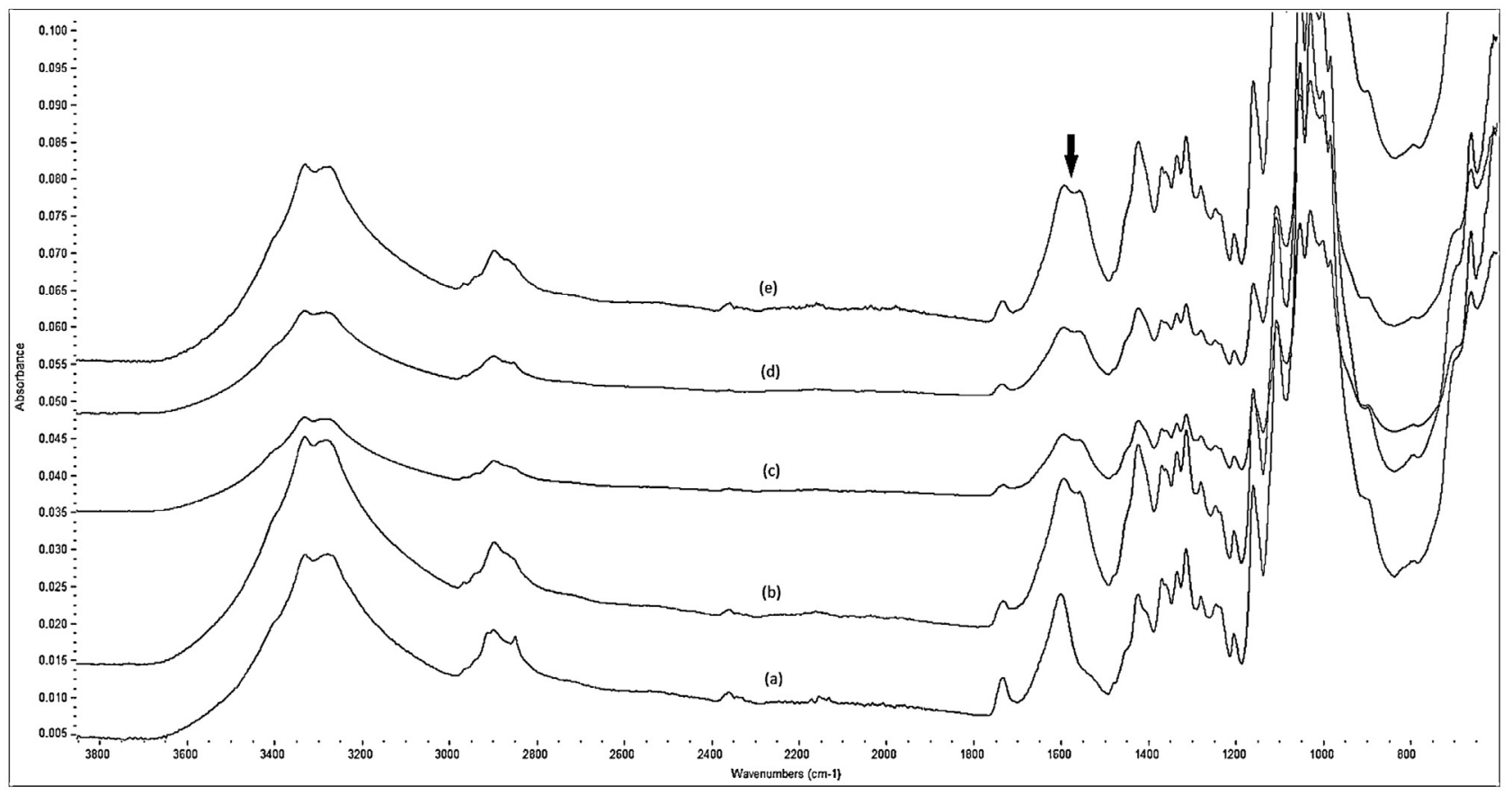

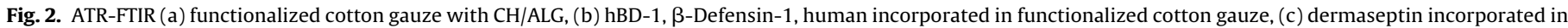
functionalized cotton gauze, (d) Cys-LC-LL-37 incorporated in functionalized cotton gauze, (e) Magainin 1 incorporated in functionalized cotton gauze.

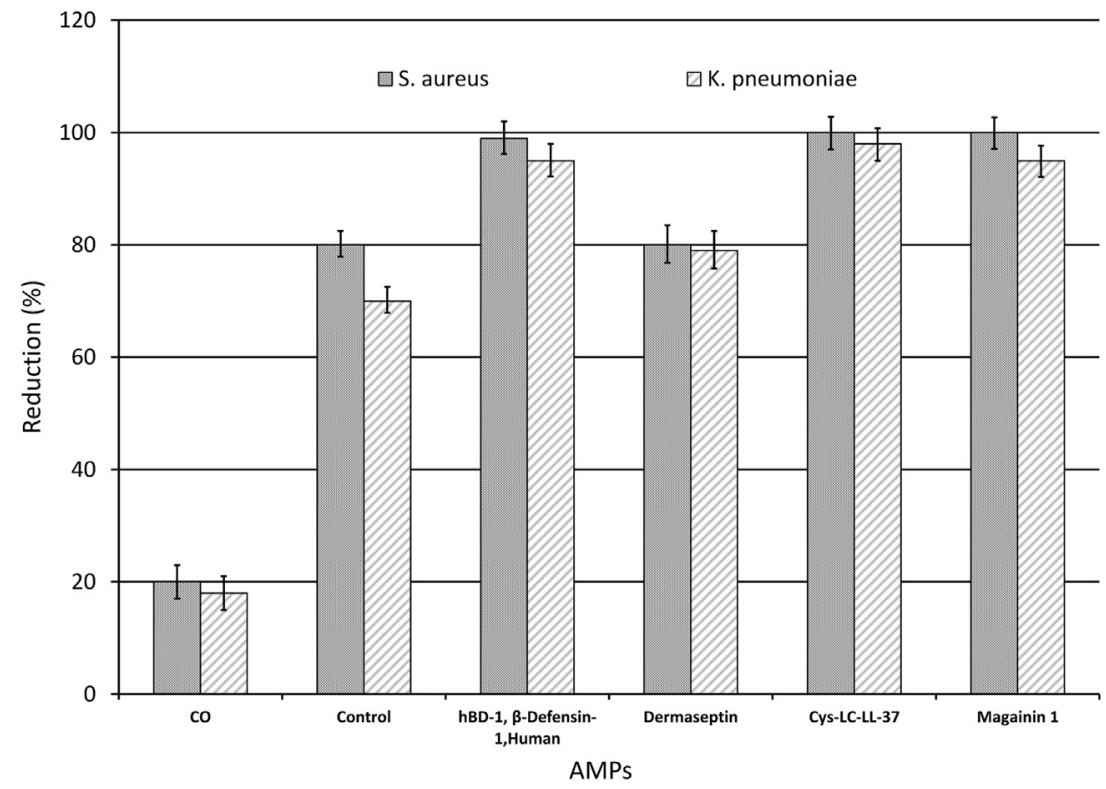

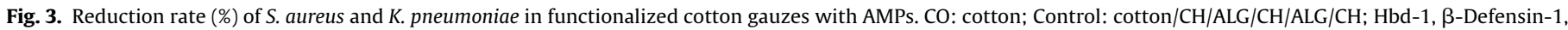
human incorporated in control; dermaseptin incorporated in control: Cys-LC-LL-37 incorporated in control; Magainin 1 incorporated in control.

reduction to be at least $\geq 99.99 \%$ ( 4 log reduction). Analyzing the results of Fig. 3, cotton gauzes with Cys-LC-LL-37 and cotton gauzes with Magainin 1 there is $6 \log$ reduction (99.9999\% reduction) against $S$. aureus, but the other samples have values below $4 \log$ reduction (99.99\%), while cotton gauzes with $\mathrm{CH} / \mathrm{ALG}$ and without AMPs have low growth inhibition rates. Incorporation of AMPs is also important due to several properties, such as:

- AMPs show broad spectrum antimicrobial activities against various microorganisms, including Gram-positive and Gramnegative bacteria, fungi and viruses (Zasloff, 2002), and have rapid onset of activity.
- Low amounts of AMPs are needed, as can be seen by the values of MIC.

- Many AMPs are effective against multi drug resistant bacteria and possess low propensity for developing resistance (Marr, Gooderham, \& Hancock, 2006; Mygind et al., 2005), probably due to their distinguished mode of action.

The problems caused by drug resistant bacteria have created an urgent need for the development of alternative therapeutics. In this respect, AMPs are considered as promising antimicrobial agents for producing new generation antibiotics. However, with all published work in the last two decades, there is no AMPs 
agent currently approved by FDA (Fjell, Hiss, Hancock, \& Schneider, 2012).

\subsection{Cytotoxicity assay}

To complement our bacterial growth inhibition studies, we performed a simple set of experiments to evaluate AMPs-loaded functionalized cotton gauzes toxicity against mammalian cell. The purpose of these experiments was to evaluate whether AMPsloaded functionalized cotton gauzes could have utility in wound healing where they would be in contact with human or animal tissue. MTT viability assay was used to determine the AMPs cytotoxicity on NHDF. Fig. 4 shows the levels of cytotoxicity exhibited by the four AMPs used in this work toward NHDF. hBD-1, $\beta$ Defensin-1 and Cys-LC-LL-37 did not exhibit cytotoxicity to NHDF at concentrations of MIC values $(5.00 \mu \mathrm{g} / \mathrm{mL})$. Such as indicated in the introduction hBD-1, $\beta$-Defensin- 1 and Cys-LC-LL-37 stimulates wound vascularization and reepithelialization of healing skin, because of this the cytotoxicity have a little value above $100 \%$. Dermaseptin at concentration of $5.00 \mu \mathrm{g} / \mathrm{mL}$ and Magainin 1 at concentration of 0.20 and $4.17 \mu \mathrm{g} / \mathrm{mL}$, there was a decrease of $5 \%$ in NHDF viability.

These results mean that none of the Dermaseptin and Magainin 1 concentrations caused cytotoxic effect in NHDF, since according to Gouveia, Sa, and Henriques (2012), only an alteration above $30 \%$ in comparison with control is considered cell-toxic (Gouveia et al., 2012). Consequently, these AMPs were considered safe to be applied as antimicrobial agents to contact with the human skin without causing any cutaneous adverse reaction in the tested concentrations. The results were statistically significant for a $p$-value $<0.05$, according to a Student's $t$-test with a $95 \%$ confidence interval. The analysis of the results (Figs. 3 and 4) showed that only cotton gauze with Cys-LC-LL-37 and with Magainin 1 has a 100\% growth inhibition for $S$. aureus and lower cytotoxicity. These results suggest that cotton gauze with Cys-LC-LL-37 and with Magainin 1 can be successfully incorporated into layers of CH/ALG and could be used for wound healing applications with minimal cytotoxicity to the surrounding tissue.

\subsection{Absorption/desorption rates of AMPs (Bradford reagent)}

The AMPs concentration in solution was calculated by comparison to a standard curve (calibration curve), formed by known concentrations of BSA. Analysis of AMPs concentrations was carried out in the solution of the incubation bath, before and after the AMPs incorporation on functionalized cotton gauzes by measuring the absorbance of the solutions.

Results showed after $6 \mathrm{~h}$ of immersion, there are higher levels of diffusion of the AMPs within functionalized cotton gauzes (Fig. 5(a)). Fig. 5(a) also shows that the diffusion of the Dermaseptin in the sample is slower, most probably due to electrostatic repulsion between the Dermaseptin and ALG, both negatively charged. After $24 \mathrm{~h}$ of incubation (immersion of functionalized cotton gauzes in the AMPs solution) the absorption rate is completed for all the peptides and the higher value is approximately $8 \mu \mathrm{g} / \mathrm{mL}$. Fig. 5(b) shows the variation in the release of AMPs over $24 \mathrm{~h}$. It is noted that the Dermaseptin has a level of faster release. In contrary, Magainin 1 has a slower release. hBD-1, $\beta$-Defensin 1 , and CysLC-LL-37 both have a gradual level of release over time. We also observed that there was a release of AMPs in solution from 5 to $6 \mu \mathrm{g} / \mathrm{mL}$. These values are higher than the values of MIC, which is an advantage, because AMPs quantities high than the MIC values should be released in order to eradicate all bacteria and prevent infection.

For the AMPs release profile, the samples were immersed in phosphate buffered saline (PBS, $\mathrm{pH}=7.0$ ) at $37^{\circ} \mathrm{C}$ in order to determine the AMPs release from cotton gauze functionalized with $\mathrm{CH}$ and ALG. The medium was completely removed periodically, at each sampling time $(1,2,3,4,6,12$ and $24 \mathrm{~h})$ and fresh medium was introduced. The results are given in cumulative release data.

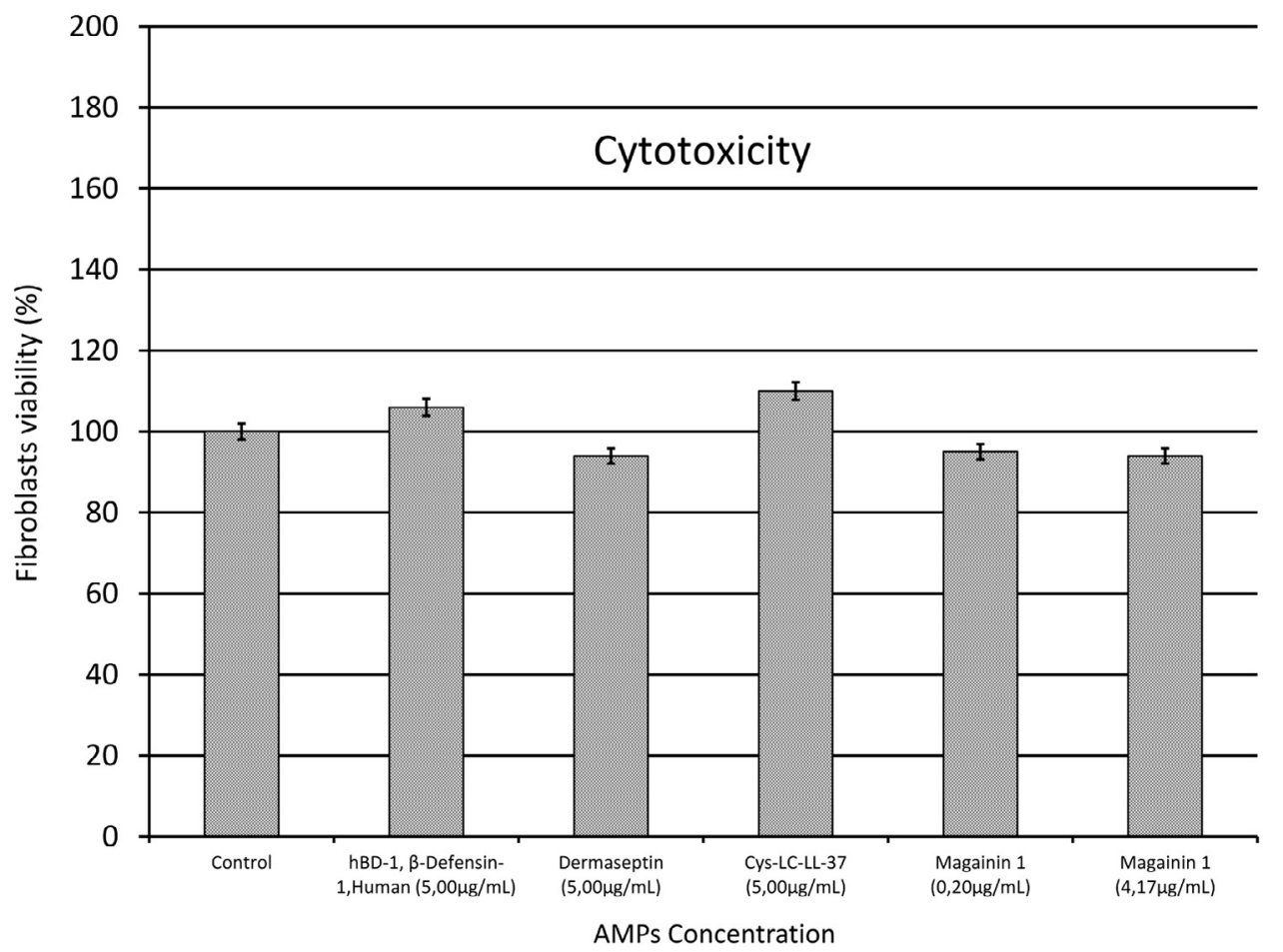

Fig. 4. Fibroblasts viability when in contact with to functionalized cotton gauzes with AMPs and with the control (functionalized cotton gauzes without AMPs). 

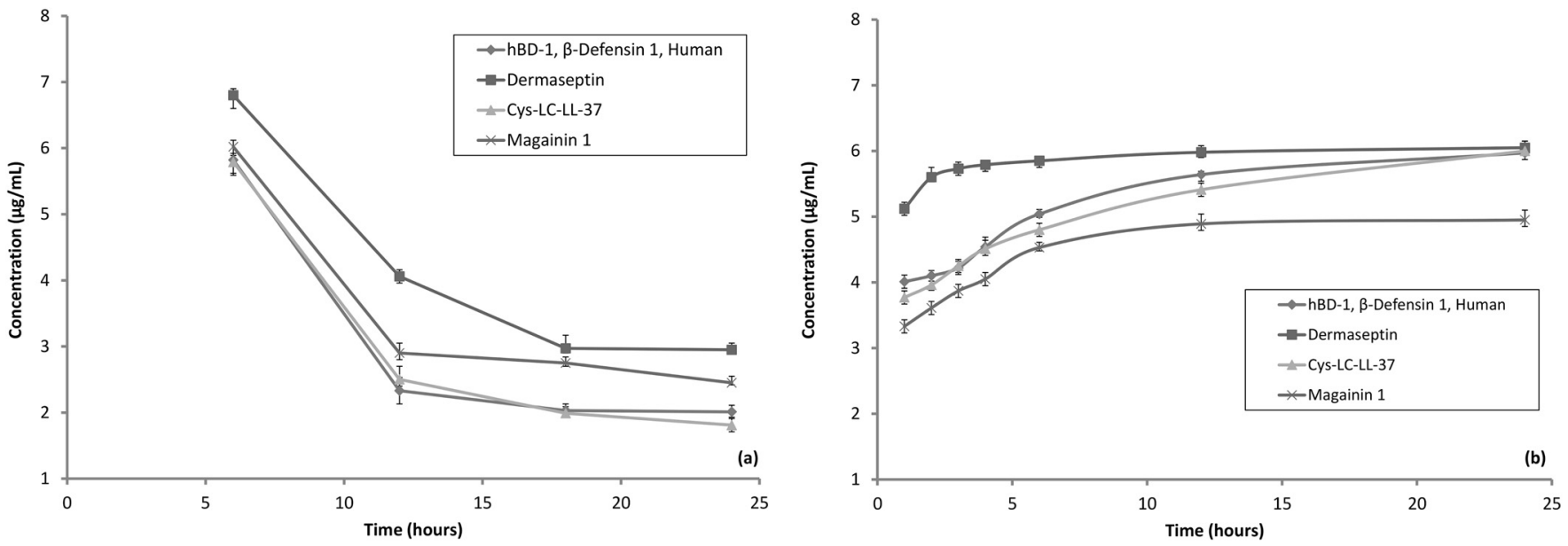

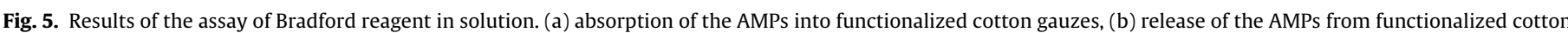
gauzes.

The AMPs release profiles obtained from the functionalized cotton gauze showed a moderate burst effect (45-67\%) during the first $6 \mathrm{~h}$, accompanied by a stage of continuous decrease in release rate during the next $18 \mathrm{~h}$. The obtained release profile can be beneficial for our application of AMPs-eluting wound dressings.

According to the work of Harrison-Balestra, Cazzaniga, Davis, \& Mertz, 2003, the onset of an infection, it is crucial to immediately respond to the presence of large numbers of bacteria (HarrisonBalestra et al., 2003). The goal of prophylactic topical antimicrobial therapy is to control microbial colonization and prevent wound infection. Unprotected burn wounds are colonized by bacteria within $12-24 \mathrm{~h}$ with microbial levels reported to reach 100 million microbes per gram of tissue within $48 \mathrm{~h}$ (Loke, Lau, Yong, Khor, \& Sum, 2000). So, during the first hour of the wound, it is essential to release a relatively high amount of antibacterial compound in order to eliminate various infections that were not eliminated during wound cleansing and might create a resistant biofilm. This work overcomes one of the major limitation regarding the delivery of antimicrobial in a biomaterial model: the effect of burst-release. Burst-release is consistent with an initial high and rapid release of the antimicrobial. It is one of the major challenges of modern drug delivery but after the first hour should continue a low release of the antimicrobial agent to healing wound.

In this work we found that during the first $6 \mathrm{~h}$ there is a high release of AMPs. From Fig. 5(a), the absorption of AMPs is approximately $8 \mu \mathrm{g} / \mathrm{mL}$ and from Fig. 5(b) the releasing of AMPs is in the range of $5-6 \mu \mathrm{g} / \mathrm{Ml}$. This implied that about $25 \%$ of the absorbed AMPs still remained in the functionalized cotton gauze after $24 \mathrm{~h}$.

Another important issue is the effect of ionic strength on the releasing of AMPs from the functionalized cotton gauze. LbL film structures are low densely packed so it allows an easy diffusion of materials through the films. In LbL multilayers constituted of weak polyelectrolytes (like chitosan and alginate) charge ratio changes drastically around their $\mathrm{p} K_{\mathrm{a}}$. Furthermore, electrostatically assembled layers are usually destabilized to a certain $\mathrm{pH}$ and ionic strength (Sato, Yoshida, Takahashi, \& Anzai, 2011). Several works in the area of delivery drugs systems using chitosan/alginate as substrate, showed that if ionic strength increased, the difference in concentration of mobile active agent between multilayers of chitosan/alginate and the surrounding media was reduced (Chen et al., 2004; Yang, Chen, Pan, Wan, \& Wang, 2013; Zhang, Wei, Lv, Wang, \& Ma, 2011). However, at pH 7.4 (near to $\mathrm{pH}$ of wound) the carboxylic acid groups of alginate hydrogel became ionized and the hydrogel can swell more significantly. The amount of active agent released at low $\mathrm{pH}$ was relatively low, while that released at high pH increased significantly. As the cotton-based bioactive gauzes are expected to be applied as wound-dressings, the phenomena above described will help in peptide release when infections are higher (higher $\mathrm{pH}$ ).

In the present work LbL cotton AMPs dressings proved to be able to decrease bacterial presence and are expected to have a similar behavior in the wound bed, thus preventing and treating infection. Consequently, in one application in which is important to have a rapid release Dermaseptin should be chosen. In order to have a gradual release, it should be used the hBD-1, $\beta$-Defensin 1 or CysLC-LL-37.

Considering the emerging need for new classes of antimicrobial agents, the AMPs represent a new alternative and may present great advantages: are usually small, have a broad spectrum of action and typically high affinity for membranes of microorganisms, they are generally protease-resistant, they have fast action and limiting the development of resistance by microorganisms.

\section{Conclusions}

We found that Magainin 1 is the AMP more potent to inhibit $S$. aureus growth, because have a lowest MIC value, but has a slower release. In contrary, Dermaseptin has a level of faster release. hBD$1, \beta$-Defensin 1, and Cys-LC-LL-37 both have a gradual level of release over time.

By ATR-FTIR analysis, we found that the AMPs are not bound to $\mathrm{CH}$ and ALG, so the AMPs are able to be released, which can be an important issue as a requirement of antimicrobial activity for a wound-dressing.

This study demonstrates that cotton gauze with Cys-LC-LL-37 and with Magainin 1 have a 100\% growth inhibition for $S$. aureus and lower cytotoxicity. These results suggest that cotton gauze with Cys-LC-LL-37 and Magainin 1 can be successfully incorporated into layers of $\mathrm{CH} / \mathrm{ALG}$ and could be used for wound healing applications with minimal cytotoxicity to the surrounding tissue. The AMPs release profile exhibited a fast effect, followed by a decreasing release rate. The release mechanism is based mainly on diffusion through the layers of CH/ALG.

Samples prepared in this study are expected to be useful in biomedicine specially in wound healing. These dressings proved to be able to decrease bacterial presence without cytotoxicity and at very low concentrations and are expected to have a similar behavior in the wound bed, thus preventing and treating infection. 


\section{Acknowledgments}

The authors would like to thank Fundação para a Ciência e Tecnologia (FCT) for the funding granted concerning the project PTDC/EBB-BIO/113671/2009 Skin2Tex. Also we would like to thank Fundo Europeu de Desenvolvimento Regional (FEDER) through (FCOMP-01-0124-FEDER-014752) COMPETE - Programa Operacional Factores de Competitividade (POFC) for the co-funding.

\section{References}

Alves, N. M., Picart, C., \& Mano, J. F. (2009). Self assembling and crosslinking of polyelectrolyte multilayer films of chitosan and alginate studied by QCM and IR spectroscopy. Macromolecular Bioscience, 9(8), 776-785.

Ariga, K., Hill, J. P., \& Ji, Q. M. (2007). Layer-by-layer assembly as a versatile bottomup nanofabrication technique for exploratory research and realistic application. Physical Chemistry Chemical Physics, 9(19), 2319-2340.

Banerjee, I., Pangule, R. C., \& Kane, R. S. (2011). Antifouling coatings: Recent developments in the design of surfaces that prevent fouling by proteins, Bacteria, and Marine Organisms. Advanced Materials, 23(6), 690-718.

Boateng, J. S., Matthews, K. H., Stevens, H. N. E., \& Eccleston, G. M. (2008). Wound healing dressings and drug delivery systems: A review. Journal of Pharmaceutical Sciences, 97(8), 2892-2923.

Boosalis, M. G., McCall, J. T., Ahrenholz, D. H., Solem, L. D., \& McClain, C. J. (1987). Serum and urinary silver levels in thermal injury patients. Surgery, 101(1), 40-43.

Bradford, M. M. (1976). Rapid and sensitive method for quantitation of microgram quantities of protein utilizing principle of protein-dye binding. Analytical Biochemistry, 72(1-2), 248-254.

Bulet, P., Stocklin, R., \& Menin, L. (2004). Anti-microbial peptides: From invertebrates to vertebrates. Immunological Reviews, 198, 169-184.

Caridade, S. G., Monge, C., Gilde, F., Boudou, T., Mano, J. F., \& Picart, C. (2013). Free-standing polyelectrolyte membranes made of chitosan and alginate. Biomacromolecules, 14(5), 1653-1660.

Carlsson, N., Borde, A., Wolfel, S., Akerman, B., \& Larsson, A. (2011). Quantification of protein concentration by the Bradford method in the presence of pharmaceutical polymers. Analytical Biochemistry, 411(1), 116-121.

Chen, S. C., Wu, Y. C., Mi, F. L., Lin, Y. H., Yu, L. C., \& Sung, H. W. (2004). A novel $\mathrm{pH}$-sensitive hydrogel composed of $\mathrm{N}$,O-carboxymethyl chitosan and alginate cross-linked by genipin for protein drug delivery. Journal of Controlled Release, 96(2), 285-300.

Chung, C., Lee, M., \& Choe, E. K. (2004). Characterization of cotton fabric scouring by FT-IR ATR spectroscopy. Carbohydrate Polymers, 58(4), 417-420.

Coates, J. (2000). Interpretation of infrared spectra, a practical approach. Encyclopedia of Analytical Chemistry,

Cookson, B. D. (1998). The emergence of mupirocin resistance: A challenge to infection control and antibiotic prescribing practice.

da Silva, F. P., \& Machado, M. C. C. (2012). Antimicrobial peptides: Clinical relevance and therapeutic implications. Peptides, 36(2), 308-314.

Dai, T., Huang, Y. Y., Sharma, S. K., Hashmi, J. T., Kurup, D. B., \& Hamblin, M. R. (2010). Topical antimicrobials for burn wound infections. Recent Pat Antiinfect Drug Discov, 5(2), 124-151.

Dang, Z., Zhang, J. G., \& Ragauskas, A. J. (2007). Characterizing TEMPO-mediated oxidation of ECF bleached softwood kraft pulps. Carbohydrate Polymers, 70(3), 310-317.

Dave, R. N., Joshi, H. M., \& Venugopalan, V. P. (2012). Biomedical evaluation of a novel nitrogen oxides releasing wound dressing. Journal of Materials Science Materials in Medicine, 23(12), 3097-3106.

de Moraes, M. A., \& Beppu, M. M. (2013). Biocomposite membranes of sodium alginate and silk fibroin fibers for biomedical applications. Journal of Applied Polymer Science, 130(5), 3451-3457.

Deng, H. B., Zhou, X., Wang, X., Zhang, C., Ding, B., Zhang, Q., et al. (2010). Layer-bylayer structured polysaccharides film-coated cellulose nanofibrous mats for cell culture. Carbohydrate Polymers, 80(2), 474-479.

De Smet, K., \& Contreras, R. (2005). Human antimicrobial peptides: Defensins, cathelicidins and histatins. Biotechnology Letters, 27(18), 1337-1347.

Decher, G. (1997). Fuzzy nanoassemblies: Toward layered polymeric multicomposites. Science, 277(5330), 1232-1237.

Diez, I., Eronen, P., Osterberg, M., Linder, M. B., Ikkala, O., \& Ras, R. H. A. (2011). Functionalization of nanofibrillated cellulose with silver nanoclusters: Fluorescence and antibacterial activity. Macromolecular Bioscience, 11(9), 1185-1191.

Elsner, J. J., Berdicevsky, I., \& Zilberman, M. (2011). In vitro microbial inhibition and cellular response to novel biodegradable composite wound dressings with controlled release of antibiotics. Acta Biomaterialia, 7(1), 325-336.

Fjell, C. D., Hiss, J. A., Hancock, R. E. W., \& Schneider, G. (2012). Designing antimicrobial peptides: Form follows function. Nature Reviews Drug Discovery, 11, 37, $11(2), 124$

Foster, A., \& DeRosa, M. C. (2014). Development of a biocompatible layer-by-layer film system using aptamer technology for smart material applications. Polymers, 6(5), 1631-1654.

Freshney, R. I. (2005). Culture of animal cells: A manual of basic technique. Hoboken, NJ: Wiley-Liss.

Gibson, A. L., Thomas-Virnig, C. L., Centanni, J. M., Schlosser, S. J., Johnston, C. E., Van Winkle, K. F., et al. (2012). Nonviral human beta defensin-3 expression in a bioengineered human skin tissue: A therapeutic alternative for infected wounds Wound Repair and Regeneration, 20(3), 414-424.

Gomes, A., Mano, J., Queiroz, J., \& Gouveia, I. (2010). Assessement of bacteria-textile interactions using Scanning Electron Microscopy: A study on LbL chitosan/alginate coated cotton. In A. Méndez-Vilas (Ed.), Microscopy: Science, technology applications and education (pp. 286-292). Spain: Formatex.

Gomes, A. P., Mano, J. F., Queiroz, J. A., \& Gouveia, I. C. (2012). Layer-by-layer deposition of antibacterial polyelectrolytes on cotton fibres. Journal of Polymers and the Environment, 20(4), 1084-1094.

Gomes, A. P., Mano, J. F., Queiroz, J. A., \& Gouveia, I. C. (2013). Layer-by-layer deposition of antimicrobial polymers on cellulosic fibers: A new strategy to develop bioactive textiles. Polymers for Advanced Technologies, 24(11), 1005-1010.

Gomes, A. P., Mano, J. F., Queiroz, J. A., \& Gouveia, I. C. (2014). New biomaterial based on cotton with incorporated biomolecules. Journal of Applied Polymer Science, 131(15).

Gouveia, I. C., Sa, D., \& Henriques, M. (2012). Functionalization of wool with Lcysteine: Process characterization and assessment of antimicrobial activity and cytotoxicity. Journal of Applied Polymer Science, 124(2), 1352-1358.

Guani-Guerra, E., Santos-Mendoza, T., Lugo-Reyes, S. O., \& Teran, L. M. (2010). Antimicrobial peptides: General overview and clinical implications in human health and disease. Clinical Immunology, 135(1), 1-11.

Harrison-Balestra, C., Cazzaniga, A. L., Davis, S. C., \& Mertz, P. M. (2003). A woundisolated Pseudomonas aeruginosa grows a biofilm in vitro within 10 hours and is visualized by light microscopy. Dermatologic Surgery, 29(6), 631-635.

Hetem, D. J., \& Bonten, M. J. M. (2013). Clinical relevance of mupirocin resistance in Staphylococcus aureus.

Hidalgo, E., \& Dominguez, C. (1998). Study of cytotoxicity mechanisms of silver nitrate in human dermal fibroblasts. Toxicology Letters, 98(3), 169-179.

Hua, Y. N. (2004). Estimating method for electron beam accelerating voltage used in energy-dispersive X-ray microanalysis: Application in failure analysis of wafer fabrication. Instrumentation Science \& Technology, 32(2), 115-126.

Hudspith, J., \& Rayatt, S. (2004). ABC of burns - First aid and treatment of minor burns. Izadpanah, A., \& Gallo, R. L. (2005). Antimicrobial peptides. Journal of the American Academy of Dermatology, 52(3), 381-392.

Jayakumar, R., Chennazhi, K. P., Muzzarelli, R. A. A., Tamura, H., Nair, S. V., \& Selvamurugan, N. (2010). Chitosan conjugated DNA nanoparticles in gene therapy Carbohydrate Polymers, 79(1), 1-8.

Jiang, Y. Y., Xiao, W., Zhu, M. X., Yang, Z. H., Pan, X. J., Zhang, Y., et al. (2012). The effect of human antibacterial peptide LL-37 in the pathogenesis of chronic obstructive pulmonary disease. Respiratory Medicine, 106(12), 1680-1689.

Johnston, A. P. R., Cortez, C., Angelatos, A. S., \& Caruso, F. (2006). Layer-by-layer engineered capsules and their applications. Current Opinion in Colloid E Interface Science, 11(4), 203-209.

Kostenko, V., Lyczak, J., Turner, K., \& Martinuzzi, R. J. (2010). Impact of silvercontaining wound dressings on bacterial biofilm viability and susceptibility to antibiotics during prolonged treatment. Antimicrobial Agents and Chemotherapy, 54(12), 5120-5131.

Kumar, T. R. S., Bai, M. V., \& Krishnan, L. K. (2004). A freeze-dried fibrin disc as a biodegradable drug release matrix.

Lee, K. Y., \& Mooney, D. J. (2012). Alginate: Properties and biomedical applications Progress in Polymer Science, 37(1), 106-126.

Lee, S., Hua, Y. A., Zhao, S. P., \& Mo, Z. Q. (2006). Studies on electron penetration versus beam acceleration voltage in energy-dispersive $\mathrm{x}$-ray microanalysis. In 2006 IEEE International Conference on Semiconductor Electronics Proceedings (pp. 610-613).

Leguen, E., Chassepot, A., Decher, G., Schaaf, P., Voegel, J. C., \& Jessel, N. (2007). Bioactive coatings based on polyelectrolyte multilayer architectures functionalized by embedded proteins, peptides or drugs. Biomolecular Engineering, 24(1), 33-41.

Li, C. L., Zhao, Y. C., Song, X. Y., Huang, X. X., \& Zhao, W. D. (2013). Molecular cloning expression and characterization of the porcine beta defensin 2 in E. coli. Protein and Peptide Letters, 20(6), 715-723.

Loke, W. K., Lau, S. K., Yong, L. L., Khor, E., \& Sum, C. K. (2000). Wound dressing with sustained anti-microbial capability. Journal of Biomedical Materials Research, 53(1), 8-17.

Marr, A. K., Gooderham, W. J., \& Hancock, R. E. W. (2006). Antibacterial peptides for therapeutic use: Obstacles and realistic outlook. Current Opinion in Pharmacology, 6(5), 468-472.

Marshall, S. H., \& Arenas, G. (2003). Antimicrobial peptides: A natural alternative to chemical antibiotics and a potential for applied biotechnology. Electronic Journal of Biotechnology, 6(3), 271-284.

Martins, G. V., Mano, J. F., \& Alves, N. M. (2010). Nanostructured self-assembled films containing chitosan fabricated at neutral pH. Carbohydrate Polymers, 80(2) 570-573.

Martins, G. V., Merino, E. G., Mano, J. F., \& Alves, N. M. (2010). Crosslink effect and albumin adsorption onto chitosan/alginate multilayered systems: An in situ QCM-D Study. Macromolecular Bioscience, 10(12), 1444-1455.

Matthew, A., Wikler, F. R. C., \& William, A. (2006). Craig Methods for dilution antimicrobial susceptibility tests for bacteria that grow aerobically; Approved standard - Seventh edition. CLSI, 26(2).

Maurstad, G., Morch, Y. A., Bausch, A. R., \& Stokke, B. T. (2008). Polyelectrolyte layer interpenetration and swelling of alginate-chitosan multilayers studied by dua wavelength reflection interference contrast microscopy. Carbohydrate Polymers, 71(4), 672-681.

Mi, F. L., Wu, Y. B., Shyu, S. S., Schoung, J. Y., Huang, Y. B., Tsai, Y. H., et al. (2002) Control of wound infections using a bilayer chitosan wound dressing with 
sustainable antibiotic delivery. Journal of Biomedical Materials Research, 59(3), 438-449.

Misra, A., \& Nanchahal, J. (2003). Use of gauze soaked in povidone iodine for dressing acute open wounds.

Moir, J., \& Serra, M. P. (2012). The use of silver nitrate in wound management.

Mocanu, G., Nichifor, M., Mihai, D., \& Oproiu, L. C. (2013). Bioactive cotton fabrics containing chitosan and biologically active substances extracted from plants. Materials Science E Engineering C - Materials for Biological Applications, 33(1), $72-77$.

Motta, G. J., Milne, C. T., \& Corbett, L. Q. (2004). Impact of antimicrobial gauze on bacterial colonies in wounds that require packing.

Mygind, P. H., Fischer, R. L., Schnorr, K. M., Hansen, M. T., Sonksen, C. P., Ludvigsen, S., et al. (2005). Plectasin is a peptide antibiotic with therapeutic potential from a saprophytic fungus. Nature, 437(7061), 975-980.

Nascimento, J. M., Franco, O. L., Oliveira, M. D. L., \& Andrade, C. A. S.(2012). Evaluation of Magainin I interactions with lipid membranes: An optical and electrochemical study. Chemistry and Physics of Lipids, 165(5), 537-544.

Nicolas, P., \& El Amri, C. (2009). The dermaseptin superfamily: A gene-based combinatorial library of antimicrobial peptides. Biochimica Et Biophysica Acta Biomembranes, 1788(8), 1537-1550.

Nizet, V., Ohtake, T., Lauth, X., Trowbridge, J., Rudisill, J., Dorschner, R. A., et al. (2001). Innate antimicrobial peptide protects the skin from invasive bacterial infection. Nature, 414(6862), 454-457.

Onaizi, S. A., \& Leong, S. S. J. (2011). Tethering antimicrobial peptides: Current status and potential challenges. Biotechnology Advances, 29(1), 67-74.

Park, S. J., \& Park, Y. M. (2010). Eco-dyeing and antimicrobial properties of chlorophyllin copper complex extracted from Sasa veitchii. Fibers and Polymers, 11(3), 357-362.

Peles, Z., Binderman, I., Berdicevsky, I., \& Zilberman, M. (2013). Soy protein films for wound-healing applications: Antibiotic release, bacterial inhibition and cellular response. Journal of Tissue Engineering and Regenerative Medicine, 7(5), $401-412$.

Quinn, J. F., Johnston, A. P. R., Such, G. K., Zelikin, A. N., \& Caruso, F. (2007). Next generation, sequentially assembled ultrathin films: Beyond electrostatics. Chemical Society Reviews, 36(5), 707-718.

Rode, H., Hanslo, D., Dewet, P. M., Millar, A. J. W., \& Cywes, S. (1989). Efficacy of mupirocin in methicillin-resistant Staphylococcus aureus burn wound-infection.

Richert, L., Lavalle, P., Payan, E., Shu, X. Z., Prestwich, G. D., Stoltz, J. F., et al. (2004). Layer by layer buildup of polysaccharide films: Physical chemistry and cellular adhesion aspects. Langmuir, 20(2), 448-458.

Saito, T., Okita, Y., Nge, T. T., Sugiyama, J., \& Isogai, A. (2006). TEMPO-mediated oxidation of native cellulose: Microscopic analysis of fibrous fractions in the oxidized products. Carbohydrate Polymers, 65(4), 435-440.

Sakamoto, N., Mukae, H., Fujii, T., Ishii, H., Yoshioka, S., Kakugawa, T., et al. (2005). Differential effects of alpha- and beta-defensin on cytokine production by cultured human bronchial epithelial cells. American Journal of Physiology - Lung Cellular and Molecular Physiology, 288(3), L508-L513.

Sato, H., \& Feix, J. B. (2006). Peptide-membrane interactions and mechanisms of membrane destruction by amphipathic $\alpha$-helical antimicrobial peptides. Biochimica et Biophysica Acta (BBA) - Biomembranes, 1758(9), 1245-1256.
Sato, K., Yoshida, K., Takahashi, S., \& Anzai, J.-I. (2011). pH- and sugar-sensitive layer-by-layer films and microcapsules for drug delivery. Advanced Drug Delivery Reviews, 63(9), 809-821.

Sinha, R., Agarwal, R. K., \& Agarwal, M. (1997). Povidone iodine plus neosporin in superficial burns - A continuing study.

Speranza, A. M., Taddei, A. R., \& Ovidi, E. (2007). In Vitro toxicity towards kiwifruit pollen of the antimicrobial peptides magainins 1 and 2. Plant Biology, 9(6), 800-806.

Standard, J. I. (2002).JIS L 1902 - Testing for antibacterial activity and efficacy on textile products. Japanese industrial standard.

Sukhishvili, S. A. (2005). Responsive polymer films and capsules via layer-by-layer assembly. Current Opinion in Colloid \& Interface Science, 10(1-2), 37-44.

Tang, Z. Y., Wang, Y., Podsiadlo, P., \& Kotov, N. A. (2006). Biomedical applications of layer-by-layer assembly: From biomimetics to tissue engineering. Advanced Materials, 18(24), 3203-3224

Thakoersing, V.S., Gooris, G. S., Mulder, A., Rietveld, M., El Ghalbzouri, A., \& Bouwstra, J. A. (2012). Unraveling barrier properties of three different in-house human skin equivalents.

Wang, Q., Fan, X. R., Gao, W. D., \& Chen, J. (2006). Characterization of bioscoured cotton fabrics using FT-IR ATR spectroscopy and microscopy techniques. Carbohydrate Research, 341(12), 2170-2175.

Wang, X. W., Wang, N. Z., Zhang, O. Z., Zapatasirvent, R. L., \& Davies, J. W. L. (1985). Tissue deposition of silver following topical use of silver sulfadiazine in extensive burns. Burns, 11(3), 197-201.

Wang, Y., Angelatos, A. S., \& Caruso, F. (2008). Template synthesis of nanostructured materials via layer-by-layer assembly. Chemistry of Materials, 20(3), $848-858$.

Wimley, W. C., \& Hristova, K. (2011). Antimicrobial peptides: Successes, challenges and unanswered questions. Journal of Membrane Biology, 239(1-2), 27-34.

Yan, H. J., Hua, Z. Z., Qian, G. S., Wang, M., Du, G. C., \& Chen, J. (2009). Analysis of the chemical composition of cotton seed coat by Fourier-transform infrared (FT-IR) microspectroscopy. Cellulose, 16(6), 1099-1107.

Yang, J., Chen, J., Pan, D., Wan, Y., \& Wang, Z. (2013). pH-sensitive interpenetrating network hydrogels based on chitosan derivatives and alginate for oral drug delivery. Carbohydrate Polymers, 92(1), 719-725.

Zairi, A., Tangy, F., Bouassida, K., \& Hani, K. (2009). Dermaseptins and magainins: Antimicrobial peptides from frogs' skin-new sources for a promising spermicides microbicides - A mini review. Journal of Biomedicine and Biotechnology, 209. Article ID 452567, 8 pp.

Zairi, A., Tangy, F., Ducos-Galand, M., Alonso, J. M., \& Hani, K. (2007). Susceptibility of Neisseria gonorrhoeae to antimicrobial peptides from amphibian skin, dermaseptin, and derivatives. Diagnostic Microbiology and Infectious Disease, 57(3), 319-324.

Zasloff, M. (2002). Antimicrobial peptides of multicellular organisms. Nature, 415(6870), 389-395.

Zhang, Y. L., Wei, W., Lv, P. P., Wang, L. Y., \& Ma, G. H. (2011). Preparation and evaluation of alginate-chitosan microspheres for oral delivery of insulin. European Journal of Pharmaceutics and Biopharmaceutics, 77(1), 11-19.

Zhao, Y., Tang, Y. W., Wang, X. G., \& Lin, T. (2010). Superhydrophobic cotton fabric fabricated by electrostatic assembly of silica nanoparticles and its remarkable buoyancy. Applied Surface Science, 256(22), 6736-6742. 